Article

\title{
Transition Metal Oxodiperoxo Complex Modified Metal-Organic Frameworks as Catalysts for the Selective Oxidation of Cyclohexane
}

\author{
Yuechao Hong ${ }^{1}$, Jie Peng ${ }^{1}$, Zhichao Sun ${ }^{1}$, Zhiquan Yu ${ }^{1}$, Anjie Wang ${ }^{1}{ }^{(\mathbb{C}, \text {, Yao Wang }}{ }^{1}$, \\ Ying-Ya Liu ${ }^{1, *}$, Fen $\mathrm{Xu}^{2}$ and Li-Xian Sun ${ }^{2}$ \\ 1 State Key Laboratory of Fine Chemicals, School of Chemical Engineering, Dalian University of Technology, \\ Dalian 116024, China; h15541172820@163.com (Y.H.); peng.jie.p4@dc.tohoku.ac.jp (J.P.); \\ sunzhichao@dlut.edu.cn (Z.S.); yuzhiquan@dlut.edu.cn (Z.Y.); ajwang@dlut.edu.cn (A.W.); \\ wangyao@dlut.edu.cn (Y.W.) \\ 2 Guangxi Key Laboratory of Information Materials and Guangxi Collaborative Innovation Center of Structure \\ and Property for New Energy and Materials, School of Material Science \& Engineering, Guilin University of \\ Electronic Technology, Guilin 541004, China; xufen@guet.edu.cn (F.X.); sunlx@guet.edu.cn (L.-X.S.) \\ * Correspondence: yingya.liu@dlut.edu.cn
}

Received: 28 December 2019; Accepted: 10 February 2020; Published: 12 February 2020

\begin{abstract}
In this work, a series of modified metal-organic frameworks (MOFs) have been prepared by pre- and post-treatment with transition metal oxodiperoxo complexes $\left(\mathrm{MoO}\left(\mathrm{O}_{2}\right)_{2}, \mathrm{WO}\left(\mathrm{O}_{2}\right)_{2}\right.$, and $\left.\mathrm{KVO}\left(\mathrm{O}_{2}\right)_{2}\right)$. The obtained materials are characterized by XRD, FTIR, SEM, TEM, inductively coupled plasma atomic emission spectrometry (ICP-AES), and X-ray photoelectron spectroscopy (XPS), as well as by $\mathrm{N}_{2}$ adsorption/desorption measurement. The characterization results show that transition metal oxodiperoxo complexes are uniformly incorporated into the MOF materials without changing the basic structures. The performance of cyclohexane oxidation on metal oxodiperoxo complex modified MOFs are evaluated. UiO-67- $\mathrm{KVO}\left(\mathrm{O}_{2}\right)_{2}$ shows the best performance for cyclohexane oxidation, with $78 \%$ selectivity to KA oil (KA oil refers to a cyclohexanol and cyclohexanone mixture) at $9.4 \%$ conversion. The KA selectivity is found to depend on reaction time, while hot-filtration experiments indicates that the catalytic process is heterogeneous with no leaching of metal species.
\end{abstract}

Keywords: metal-organic framework; cyclohexane oxidation; transition metal oxodiperoxo complexes; cyclohexanol; cyclohexanone

\section{Introduction}

Selective C-H oxidation is of crucial importance in activating raw materials to produce oxygenates in many industrial processes [1,2]. The oxidation of cyclohexane is the main industrial process to obtain a mixture of cyclohexanone (Cyone) and cyclohexanol $(\mathrm{CyOH})$ (referred to as KA oil of ketone and alcohol mixture), which are important intermediates in the production of Nylon-6 and Nylon-66 [3-5], and are also raw materials for the production of caprolactam and adipic acid [6]. In the oxidation process, the deep oxidation often results in the formation of undesired by-products [7]. In the industrial process, reasonable selectivity to the desired intermediate KA oil is achieved at a lower conversion $[8,9]$. Therefore, the selective oxidation of cyclohexane at mild condition with high energy efficiency is one of the major needs and biggest challenges for sustainable industry $[10,11]$. To tackle this issue, there is an urgent need for efficient, high selectivity, environmentally benign catalysts towards the sustainable development of such an important oxidation process [12]. Primarily, there are two commercial processes in cyclohexane oxidation: The non-catalytic autoxidation process and the catalyzed process [13]. In both processes, radical chemistry plays a major role. Many transition 
metals (Ti, V, Cr, Co, Mn, Fe, Mo) in their oxide forms [14-16] are used as catalyst in cyclohexane oxidation reactions, and silica-based material is a common choice as the catalyst support [17-21]. For instance, a mesoporous siliceous material, TUD-1, has been functionalized by different metals, and the obtained M-TUD-1 ( $\mathrm{M}=\mathrm{Co}, \mathrm{Cr}, \mathrm{Cu}, \mathrm{Mn}, \mathrm{Mo}$, Ti, and $\mathrm{V}$ ) was examined in the liquid phase oxidation of cyclohexane with tert-butyl hydroperoxide (TBHP) as the oxidant. Co-TUD-1 has shown good catalytic activity in cyclohexane conversion, but the radical product, cyclohexyl hydroperoxide (CHHP), is produced in large amounts [22,23]. In a recent study, by introducing a second metal $(\mathrm{Mn}, \mathrm{Ti}, \mathrm{V}, \mathrm{or} \mathrm{Bi})$ into Co-TUD-1, the bimetallic TUD-1 showed higher activity and less selectivity towards CHHP in the oxidation of cyclohexane [21]. During the study, metal leaching was one of the main problems in the liquid phase oxidation of cyclohexane because the impregnation, ion-exchange, or isomorphous substitution cannot form strong bonding between the metal species and the support [24-26].

Metal-organic frameworks (MOFs) have received extensive attention in the field of heterogeneous catalysis due to their high porosity, abundant pore structure, large specific surface area, and easy modification [27-29]. MOFs are crystalline materials constructed by linking multidentate ligands with metal/cluster nodes to form infinite networks. The strong coordination interactions between metal and ligand and the infinite three-dimensional structures ensure the good chemical stability of the MOFs and allow for rational design and synthesis [30]. 2,2'-Bipyridine (bpy) is one of the most widely used bidentate chelators in transition metal coordination chemistry [31]. It is very interesting and useful for combining the excellent hydrocarbon oxidation properties of transition metals with the superior properties of MOFs. In our previous work, a molybdenum complex, $\mathrm{MoO}_{2} \mathrm{Cl}_{2}$, was tethered to the bipyridine linkers of a Ga-MOF (COMOC-4), where the catalyst showed high performance in the liquid phase oxidation reactions, such as epoxidation of cycloalkenes and oxidation of polyaromatic sulfur compounds [32,33]. Lin's group also worked on MOFs of UiO topology containing a bipyridine ligand by anchoring Ir complexes onto the MOFs, and their catalyst showed superior activity and reusability in $\mathrm{C}-\mathrm{H}$ activation [34]. Most recently, by loading polyoxovanadates (POVs) onto MOFs, mixed-valence $\{$ V16\} [35] cluster-based MOF catalysts were prepared, which showed remarkable catalytic performance ( $24.6 \%$ conversion with $99 \%$ selectivity to KA oil) in the aerobic oxidation of cyclohexane. The results also showed that the mixed-valence $\{$ V16\} cluster exhibited higher activity than the homovalent vanadium cluster. In this work, a metal-organic framework, UiO-67, with linker replaced by 2,2'-bipyridine-5,5'-dicarboxylate (UiO-67-bpydc) (Scheme 1) was used as the solid support. Zr-based MOFs are known for their exceptional thermal, chemical, and mechanical stability properties, which are important for catalytic applications [36]. Among them was a Universuty of Oslo (UiO) series of $\mathrm{Zr}$-based MOFs comprising 12-connected $\mathrm{Zr}_{6}$-oxide nodes, featuring an fcu topology. The pore aperture size of UiO-67 is between 8 and $11.5 \AA$, allowing further functionalization [37,38]. The original UiO-67 was reported with biphenol dicarboxylate ligand; with 2,2' -bipyridine-5,5' -dicarboxylate as the replacing ligand, it is easy to introduce metal active components onto the bipyridine nitrogen for functionalization due to its own chelation sites. Herein, a series of active components, peroxo vanadates $(\mathrm{pV})$, peroxo compounds of molybdenum ( $\mathrm{pMo})$, and tungsten $(\mathrm{pW})$, were anchored via $2,2^{\prime}$-bipyridine sites. The catalytic activity of the obtained materials, namely UiO-67- $\mathrm{MO}\left(\mathrm{O}_{2}\right)_{2}(\mathrm{M}=\mathrm{Mo}$, $\mathrm{W}, \mathrm{V})$, were evaluated in the liquid phase oxidation of cyclohexane. 


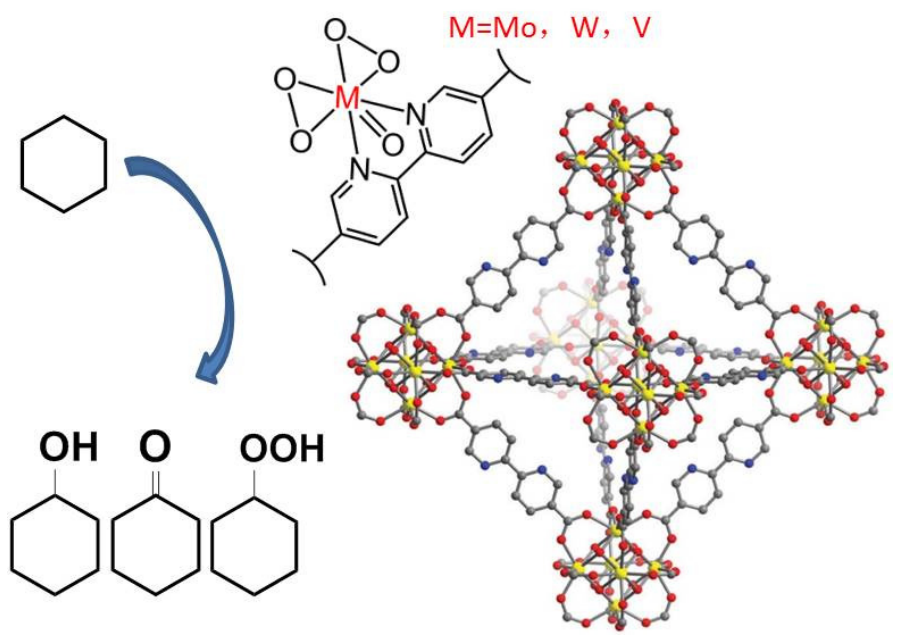

Scheme 1. Illustration of modified UiO-67 as a catalyst for the selective oxidation of cyclohexane.

\section{Material and Methods}

\subsection{Material}

2,2'-bipyridine-5, $5^{\prime}$-dicarboxylic acid $\left(\mathrm{H}_{2}\right.$ bpydc) was prepared following a published method [39]. $\mathrm{MoO}\left(\mathrm{O}_{2}\right)_{2} \cdot 2 \mathrm{DMF}$ (DMF $=N, N$-dimethylformamide) was prepared according to the published procedure [40]. All other chemicals were obtained commercially and used without further purification.

The powder X-ray diffraction (XRD) patterns were recorded on a Rigaku D-Max-2400 diffractometer using $\mathrm{Cu} \mathrm{K} \alpha$ radiation at $40 \mathrm{kV}$ and $100 \mathrm{~mA}$. The metal content in the samples was determined by inductively coupled plasma atomic emission spectrometry (ICP-AES) (Optima 2000DV). Fourier transform infrared spectra (FTIR) was recorded on an FT-IR-800 spectrometer in KBr disks at room temperature. The specific surface area of the catalyst was determined by $\mathrm{N}_{2}$ adsorption/desorption isotherm using a Tristar II 3020 adsorption analyzer (The data are treated according to the Brunauer, Emmett and Teller (BET) adsorption isotherm equation). Before the measurement, the sample was degassed at $120{ }^{\circ} \mathrm{C}$ under vacuum overnight. The morphology and structures of the catalysts were characterized using scanning electron microscopy (SEM) (NOVA nanoSEM 450). X-ray photoelectron spectroscopy (XPS) measurements were recorded on a Multilab 2000 X-ray photoelectron spectrometer using an $\mathrm{Al} \mathrm{K} \alpha$ source. The binding energies of all the observed peaks were calibrated towards a value for the C $1 \mathrm{~s}$ peak of adventitious carbon at $284.6 \mathrm{eV}$.

\subsection{Catalyst Preparation}

\subsubsection{Synthesis of UiO-67-bpydc}

UiO-67-bpydc (1) was synthesized according to a reported procedure with slight modification [31]. A mixture of $\mathrm{ZrCl}_{4}(0.245 \mathrm{~g}, 1.05 \mathrm{mmol}), \mathrm{H}_{2}$ bpydc $(0.256 \mathrm{~g}, 1.05 \mathrm{mmol})$, acetic acid (HOAc) $(1.8 \mathrm{~mL})$, and DMF (50 mL) was added in a Schlenk flask and sonicated for $20 \mathrm{~min}$, then sealed and held at $120^{\circ} \mathrm{C}$ for $24 \mathrm{~h}$ under stirring. After cooling down to room temperature, the precipitate was isolated by centrifugation. The powder product was suspended in DMF $(50 \mathrm{~mL})$ at $80^{\circ} \mathrm{C}$ for $3 \mathrm{~h}$ under stirring and isolated by centrifugation. The obtained white powder was washed by ethanol twice and dried at $100{ }^{\circ} \mathrm{C}$ overnight (yield: $89 \%$ based on $\mathrm{Zr}$ ).

\subsubsection{Synthesis of $\mathrm{UiO}-67-\mathrm{MoO}\left(\mathrm{O}_{2}\right)_{2}$}

$\mathrm{UiO}-67-\mathrm{MoO}\left(\mathrm{O}_{2}\right)_{2}$ (2) was prepared by post-synthetic modification following a reported procedure [40]. Typically, $\mathrm{MoO}\left(\mathrm{O}_{2}\right)_{2} \cdot 2 \mathrm{DMF}(0.36 \mathrm{~g}, 1.12 \mathrm{mmol})$ was fully dissolved in ethanol $(80 \mathrm{~mL})$ under vigorous stirring, and $1(0.4 \mathrm{~g}, 0.187 \mathrm{mmol})$ was added into the solution and stirred vigorously at $80{ }^{\circ} \mathrm{C}$ for $24 \mathrm{~h}$. 
The solution was cooled to room temperature and the precipitate was isolated by centrifugation. The solid product was washed by ethanol twice and dried at $100{ }^{\circ} \mathrm{C}$ overnight (yield: $85 \%$ based on UiO-67).

\subsubsection{Synthesis of $\mathrm{UiO}-67-\mathrm{WO}\left(\mathrm{O}_{2}\right)_{2}$}

UiO-67- $\mathrm{WO}\left(\mathrm{O}_{2}\right)_{2}$ (3) was synthesized by preparing the partially metalated ligand and then building the MOF structure. Peroxotungstate solution was prepared following a reported procedure with modification [41]. A mixture of $\mathrm{H}_{2} \mathrm{WO}_{4}(4.5 \mathrm{~g}, 18 \mathrm{mmol})$ and $\mathrm{H}_{2} \mathrm{O}_{2}(40 \mathrm{~mL}, 30 \%$ by weight solution) was stirred at $45^{\circ} \mathrm{C}$ for $24 \mathrm{~h}$. Then the solution was centrifuged and the supernatant liquid was placed in the refrigerator $\left(2{ }^{\circ} \mathrm{C}-4{ }^{\circ} \mathrm{C}\right)$ prior to use. $\mathrm{H}_{2}$ bpydc $(1 \mathrm{~g}, 4.1 \mathrm{mmol})$ was added into the supernatant $(20 \mathrm{~mL})$ and then stirred at room temperature for $24 \mathrm{~h}$. The solution was centrifuged, and the solid was washed by ethanol twice. After drying at $100{ }^{\circ} \mathrm{C}$ overnight, $\mathrm{H}_{2}$ bpydc- $\mathrm{WO}\left(\mathrm{O}_{2}\right)_{2}$ precursor was obtained with a yield of $0.98 \mathrm{~g}$.

A mixture of $\mathrm{ZrCl}_{4}(0.245 \mathrm{~g}, 1.05 \mathrm{mmol}), \mathrm{H}_{2}$ bpydc-WO$\left(\mathrm{O}_{2}\right)_{2}(0.534 \mathrm{~g}), \mathrm{HOAc}(1.8 \mathrm{~mL})$, and DMF $(50 \mathrm{~mL})$ was added in a Schlenk flask and sonicated for $20 \mathrm{~min}$, then sealed and stirred at $120^{\circ} \mathrm{C}$ for $24 \mathrm{~h}$. The solution was cooled to room temperature, and the precipitate was isolated by centrifugation. The solid product was washed by DMF once, followed by ethanol twice and finally dried at $100{ }^{\circ} \mathrm{C}$ overnight. (yield: $82 \%$ based on $\mathrm{Zr}$ ).

\subsubsection{Synthesis of $\mathrm{UiO}-67-\mathrm{KVO}\left(\mathrm{O}_{2}\right)_{2}$}

UiO-67-KVO $\left(\mathrm{O}_{2}\right)_{2}(4)$ was synthesized by preparing the partially metalated ligand and then building the MOF structure. Peroxovanadate precursor solution was prepared following the reported procedure with modification [42]. $\mathrm{H}_{2}$ bpydc $(0.2442 \mathrm{~g}$, $1 \mathrm{mmol})$ was added into ethanol $(20 \mathrm{~mL})$ and suspended using ultrasound for $30 \mathrm{~min}$ to form a suspension (a). $\mathrm{KVO}_{3}(0.138 \mathrm{~g}, 1 \mathrm{mmol})$ was dissolved into $\mathrm{H}_{2} \mathrm{O}_{2}(10 \mathrm{~mL})$ in a beaker to give a solution (b) by stirring in an ice water bath. All steps described subsequently in this paragraph were operated in an ice water bath. Solution a was added drop wise into solution $\mathbf{b}$, with constant stirring. After the addition was completed, the yellow mixture was stirred for $5 \mathrm{~min}$, then $10 \mathrm{~mL}$ of cold ethanol was added. After $10 \mathrm{~min}$, the mixture was allowed to stand for $15 \mathrm{~min}$ for stratification. Then, another $10 \mathrm{~mL}$ of cold ethanol was added, and the mixture was stirred for $10 \mathrm{~min}$ and then left to stand for another $10 \mathrm{~min}$. The solid product was isolated by centrifugation and washed by ethanol twice and finally dried at room temperature in vacuum. We then obtained the light yellow $\mathrm{H}_{2}$ bpydc- $\mathrm{KVO}\left(\mathrm{O}_{2}\right)_{2}$ precursor with a yield of $0.25 \mathrm{~g}$.

A mixture of the obtained solid $\left(\mathrm{H}_{2}\right.$ bpydc- $\left.\mathrm{KVO}\left(\mathrm{O}_{2}\right)_{2}, 0.171 \mathrm{~g}\right), \mathrm{ZrCl}_{4}(0.082 \mathrm{~g}, 0.35 \mathrm{mmol}), \mathrm{HOAc}$ $(0.6 \mathrm{~mL})$, and DMF $(17 \mathrm{~mL})$ was added in a sealed glass flask and sonicated for $20 \mathrm{~min}$; it was then stirred at $120^{\circ} \mathrm{C}$ for $24 \mathrm{~h}$. The solution was cooled to room temperature and the precipitate was isolated by centrifugation. The solid product was washed by DMF once and by ethanol twice and finally dried at $80^{\circ} \mathrm{C}$ overnight. (yield: $88 \%$ based on $\mathrm{Zr}$ ).

\subsection{Catalytic Oxidation of Cyclohexane}

The oxidation of cyclohexane was performed in a $35 \mathrm{~mL}$ Pyrex tube under stirring. In a typical reaction, the cyclohexane $(8 \mathrm{mmol})$, tert-butyl hydroperoxide (TBHP, $8 \mathrm{mmol}, 70 \mathrm{wt} \%$ in water), and 1,2,4-trichlorobenzene $(2.78 \mathrm{mmol})$ (the internal standard) were added into $8 \mathrm{~mL}$ acetonitrile. UiO-67-MO $\left(\mathrm{O}_{2}\right)_{2}(\mathrm{M}=\mathrm{Mo}, \mathrm{W}, \mathrm{V})$ was added as a catalyst with a molar ratio of the second metal to cyclohexane of 1:266. After the reaction, the spent catalyst was separated by centrifugation and washed with acetone, dried at room temperature, and subsequently reused.

\subsection{Product Analysis}

The oxidation products include the target products $\mathrm{CyOH}$ and Cyone, a radical product, $\mathrm{CHHP}$, and by-products such as organic acids and esters. In our catalytic reaction system, only organic acid was detected, and no ester product was found in the titration. 
(1) $\mathrm{CyOH}$ and Cyone

Cyclohexane, $\mathrm{CyOH}$, and Cyone were analyzed by gas chromatography (GC) with HP-5 capillary column $(30 \mathrm{~m} \times 0.32 \mathrm{~mm})$. Quantitative analysis of cyclohexane, $\mathrm{CyOH}$, and Cyone was performed by the internal standard curve method.

(2) Peroxide

The peroxides in the reaction solution included the oxidant TBHP and the intermediate product $\mathrm{CHHP}$, which were quantified by an indirect iodometric method. The peroxide concentration was calculated as follows:

$$
\mathrm{C}=\frac{\left(\mathrm{V}-\mathrm{V}_{0}\right) \times \mathrm{C}_{0}}{2 \times \mathrm{V}_{\text {sample }}}
$$

where $\mathrm{C}$ is the peroxide concentration, $\mathrm{mol} / \mathrm{L} ; \mathrm{V}$ is the consumption sodium thiosulfate $\left(\mathrm{Na}_{2} \mathrm{~S}_{2} \mathrm{O}_{3}\right)$ standard solution volume, $\mathrm{mL} ; \mathrm{V}_{0}$ is the blank experiment consumption $\mathrm{Na}_{2} \mathrm{~S}_{2} \mathrm{O}_{3}$ standard solution volume, $\mathrm{mL} ; \mathrm{C}_{0}$ is the $\mathrm{Na}_{2} \mathrm{~S}_{2} \mathrm{O}_{3}$ standard solution concentration, and $\mathrm{mol} / \mathrm{L} ; \mathrm{V}_{\text {sample }}$ is the sample volume, $\mathrm{mL}$.

\section{(3) $\mathrm{CHHP}$}

The radical product, $\mathrm{CHHP}$, is thermally unstable and will be partially decomposed into $\mathrm{CyOH}$ and Cyone in GC, which affects the analysis results. An excess of triphenylphosphine $\left(\mathrm{PPh}_{3}\right)$ was added to the sample to completely reduce $\mathrm{CHHP}$ to $\mathrm{CyOH}$, and the CHHP content was calculated by chromatography before and after $\mathrm{PPh}_{3}$ addition. The simplified formula is:

$$
[\mathrm{A}]_{\mathrm{PPh} 3}=[\mathrm{A}]+[\mathrm{CHHP}]
$$

where $[\mathrm{A}]_{\mathrm{PPh} 3}$ is the result of chromatographic analysis of $\mathrm{CyOH}$ after the addition of $\mathrm{PPh}_{3} ;[\mathrm{A}]$ is the result of chromatographic analysis of $\mathrm{CyOH}$ before the addition of $\mathrm{PPh}_{3}$; and [CHHP] is CHHP content.

\section{Results and Discussion}

\subsection{Synthesis and Characterization}

\subsubsection{Synthesis}

UiO-67-MoO $\left(\mathrm{O}_{2}\right)_{2}$ is prepared by treating a suspension of the pristine UiO-67 in ethanol with $\mathrm{MoO}\left(\mathrm{O}_{2}\right)_{2} \cdot 2 \mathrm{DMF}$. This post-synthetic approach was commonly used to provide MOFs with new functionalities by a solid-liquid reaction [43]. However, the attempt to prepare UiO-67-WO( $\left(\mathrm{O}_{2}\right)_{2}$ and $\mathrm{UiO}-67-\mathrm{KVO}\left(\mathrm{O}_{2}\right)_{2}$ by post-synthetic modification was not successful because $\mathrm{WO}\left(\mathrm{O}_{2}\right)_{2}$ and $\mathrm{KVO}\left(\mathrm{O}_{2}\right)_{2}$ complexes can only form a stable solution in concentrated hydrogen peroxide solution, where the MOF structure cannot survive in such a harsh condition. Alternatively, UiO-67-WO( $\left(\mathrm{O}_{2}\right)_{2}$ and UiO-67- $\mathrm{KVO}\left(\mathrm{O}_{2}\right)_{2}$ are both prepared by coordinating first with the organic ligand and then by building the MOF structure. The $\mathrm{WO}\left(\mathrm{O}_{2}\right)_{2}$ and $\mathrm{KVO}\left(\mathrm{O}_{2}\right)_{2}$ anchored organic ligand were prepared by the standard synthetic method for complexes of the type $\left[\mathrm{MO}\left(\mathrm{O}_{2}\right)_{2} \mathrm{~L}\right](\mathrm{L}=$ organic ligand), which involves adding the organic ligand $\left(\mathrm{H}_{2}\right.$ bpydc in our case) to the aqueous solution containing the $\left[\mathrm{MO}\left(\mathrm{O}_{2}\right)_{2}(\mathrm{M}=\mathrm{W}\right.$ and $\left.\mathrm{V})\right]$ complex and a large excess of $\mathrm{H}_{2} \mathrm{O}_{2}[41,42]$. Please note that the anchoring procedure of the organic ligand is incomplete; only part of the ligand was successfully functionalized. ICP and elemental analysis showed that the metalated linker has a doping molar ratio of 0.31 for $\mathrm{W}$ and 0.35 for V (Table S1, Supplementary Material), FTIR spectra of $\mathrm{H}_{2}$ bpydc after metalation showed a band at $1684 \mathrm{~cm}^{-1}$, which was assigned to the $-\mathrm{COOH}$ stretching vibration (Figure S1, Supplementary Material). The characterization demonstrated that the free carboxylic acid group is still available for further coordination with $\mathrm{Zr}$ salt to build the MOF framework. However, such a mixed-ligand was sufficient enough to build the MOF framework containing certain amounts of oxodiperoxo complexes. 


\subsubsection{XRD Characterization}

In Figure 1, the simulated XRD pattern of UiO-67 derived from single-crystal x-ray diffraction data and the experimentally synthesized $\mathrm{UiO}-67$ before and after modification are compared. The crystal structure of the experimentally synthesized MOF material was consistent with the simulated XRD pattern, indicating that the structural integrity was well preserved after modification. After anchoring $\mathrm{MoO}\left(\mathrm{O}_{2}\right)_{2}, \mathrm{WO}\left(\mathrm{O}_{2}\right)_{2}$, and $\mathrm{KVO}\left(\mathrm{O}_{2}\right)_{2}$, the position of the diffraction peak was unchanged, but the intensity was decreased, especially for $\mathrm{UiO}-67-\mathrm{KVO}\left(\mathrm{O}_{2}\right)_{2}$. However, no additional diffraction peak appeared. It indicates that the MOF material had a decreased crystallinity after metal peroxide modification, but the framework structure was intact. The supported transition metal peroxide was highly dispersed on the MOF framework, and there was no characteristic diffraction of the transition metal oxide or metal complexes.

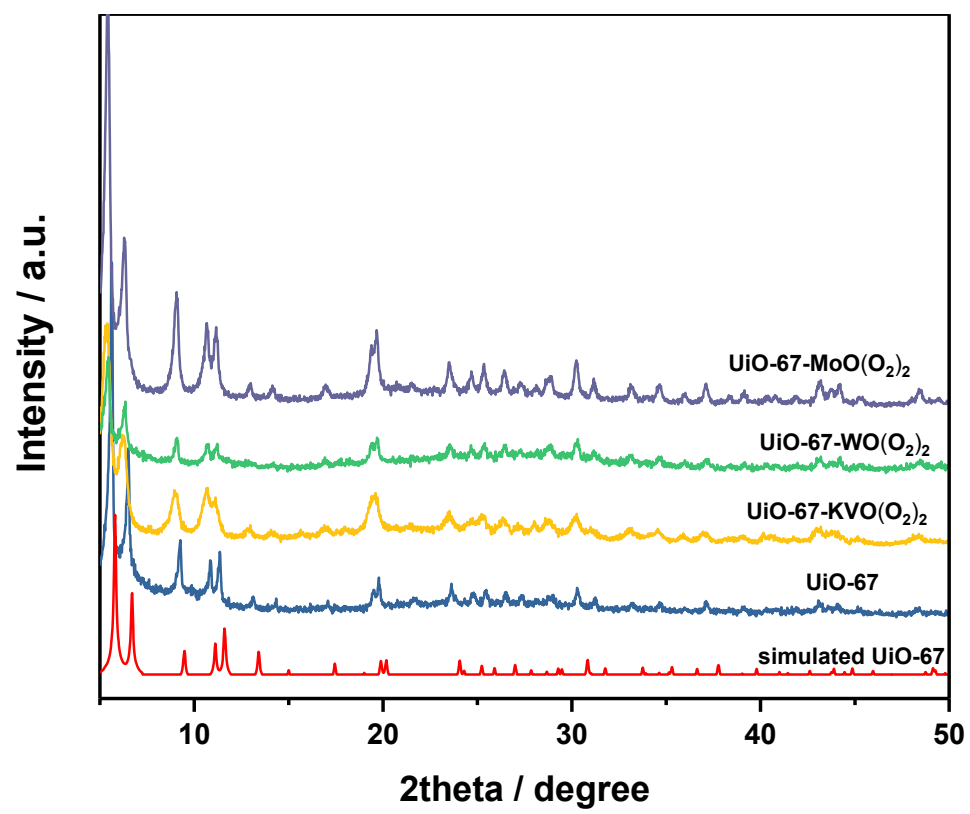

Figure 1. XRD patterns of the simulated UiO-67 and the synthesized $\mathrm{UiO}-67, \mathrm{UiO}-67-\mathrm{MoO}\left(\mathrm{O}_{2}\right)_{2}$, $\mathrm{UiO}-67-\mathrm{WO}\left(\mathrm{O}_{2}\right)_{2}$, and $\mathrm{UiO}-67-\mathrm{KVO}\left(\mathrm{O}_{2}\right)_{2}$.

\subsubsection{Nitrogen Physical Adsorption, ICP-AES, and FTIR Studies}

The metal loading of the modified MOF materials and BET specific surface areas are listed in Table 1. The loadings of Mo, W, and V were determined by ICP analysis and were $14.1 \mathrm{wt} \%, 6.3 \mathrm{wt} \%$, and $2.7 \mathrm{wt} \%$, respectively. It should be noted that, although the $\mathrm{MoO}\left(\mathrm{O}_{2}\right)_{2}$ was tethered on the framework by post-synthetic modification, the loading of the Mo complex was very high. There were $4.2 \mathrm{MoO}\left(\mathrm{O}_{2}\right)_{2}$ molecules in one $\mathrm{UiO}-67$ structural unit (Table 1). The $\mathrm{WO}\left(\mathrm{O}_{2}\right)_{2}$ and $\mathrm{KVO}\left(\mathrm{O}_{2}\right)_{2}$ complexes were anchored on the MOF frameworks by coordinating first with the organic ligand and then by building the MOF structure. There were certain losses of metal oxodiperoxo complexes during the formation of MOFs, as evidenced by ICP and elemental analysis. Metalated ligand has a metal to ligand molar ratio of 0.35 for V (Table S1, Supplementary Material), while UiO-67- $\mathrm{KVO}\left(\mathrm{O}_{2}\right)_{2}$ has a metal to MOF molar ratio of 1.2 , which indicates that there is $57 \%$ of $\mathrm{KVO}\left(\mathrm{O}_{2}\right)_{2}$ remaining on the MOF framework. Similarly, $43 \%$ of $\mathrm{WO}\left(\mathrm{O}_{2}\right)_{2}$ was anchored onto the MOF framework compared to the partially metalated linker. The BET specific surface area of UiO-67 was $1562 \mathrm{~m}^{2} / \mathrm{g}$, and after pre- and post-modification, the surface areas of $\mathrm{UiO}-67-\mathrm{MoO}\left(\mathrm{O}_{2}\right)_{2}, \mathrm{UiO}-67-\mathrm{WO}\left(\mathrm{O}_{2}\right)_{2}$, and $\mathrm{UiO}-67-\mathrm{KVO}\left(\mathrm{O}_{2}\right)_{2}$ significantly reduced to $583 \mathrm{~m}^{2} / \mathrm{g}, 656 \mathrm{~m}^{2} / \mathrm{g}$, and $305 \mathrm{~m}^{2} / \mathrm{g}$, respectively, which may be due to the fact that the metal complexes can occupy and/or block the cavities of the UiO-67, and the MOF structure partially collapsed during the modification process. As shown in Figure S2 (Supplementary Material), $\mathrm{UiO}-67-\mathrm{MoO}\left(\mathrm{O}_{2}\right)_{2}$ and $\mathrm{UiO}-67-\mathrm{KVO}\left(\mathrm{O}_{2}\right)_{2}$, when prepared with different procedures activated by 
heating $\left(100{ }^{\circ} \mathrm{C}\right)$, have both shown certain losses in crystallinity compared to room temperature activation. The decrease in surface area was in agreement with the XRD results, indicating that there was certain loss in crystallinity during every step of the modification process.

Figure 2 presents a summary of the FTIR spectra of the metal peroxide-modified UiO-67 in comparison with that of the pristine MOF. The band at $950 \mathrm{~cm}^{-1}$ is attributed to the $\mathrm{Mo}=\mathrm{O}$ double bond stretching vibration in the octahedral molybdenum peroxide species in UiO-67-MoO( $\left(\mathrm{O}_{2}\right)_{2}$. The bands at $573 \mathrm{~cm}^{-1}$ and $536 \mathrm{~cm}^{-1}$ correspond to Mo-O with asymmetric and symmetric stretching vibration [40]. The band at $953 \mathrm{~cm}^{-1}$ is assigned to the $\mathrm{W}=\mathrm{O}$ stretching vibration in the octahedral tungsten peroxide species in $\mathrm{UiO}-67-\mathrm{WO}\left(\mathrm{O}_{2}\right)_{2}$, and the bands centered at $573 \mathrm{~cm}^{-1}$ and $531 \mathrm{~cm}^{-1}$ are attribute to the asymmetric and symmetric stretching vibration of $\mathrm{W}-\mathrm{O}$ [41]. The bands at $987 \mathrm{~cm}^{-1}$ and $954 \mathrm{~cm}^{-1}$ are assigned to $\mathrm{V}=\mathrm{O}$ double bond stretching vibrations in octahedral vanadium peroxide species in UiO-67-KVO $\left(\mathrm{O}_{2}\right)_{2}$. The bands at $568 \mathrm{~cm}^{-1}$ and $533 \mathrm{~cm}^{-1}$ correspond to the vibration of $\mathrm{V}-\mathrm{O}$ [44]. In all spectra of UiO-67-MO(O $\left.\mathrm{O}_{2}\right)_{2}(\mathrm{M}=\mathrm{Mo}, \mathrm{W}, \mathrm{V})$, shoulder bands at $859 \mathrm{~cm}^{-1}$ and $848 \mathrm{~cm}^{-1}$ correspond to the vibration of $\mathrm{O}-\mathrm{O}[41,44]$, all pointing to the fact that peroxide species were present in the modified UiO-67 materials.
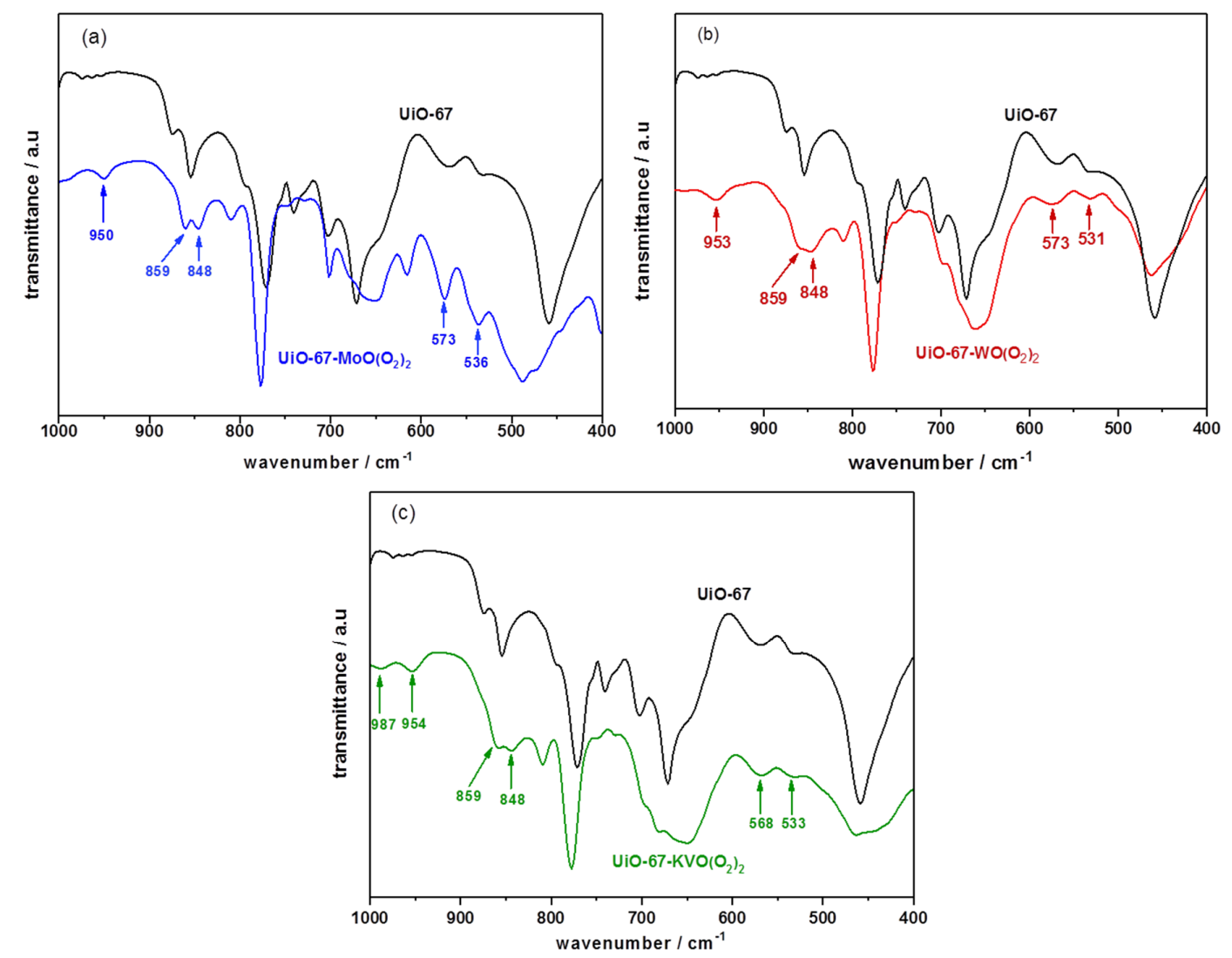

Figure 2. FTIR spectra of $\mathrm{UiO}-67$, $\mathrm{UiO}-67-\mathrm{MoO}\left(\mathrm{O}_{2}\right)_{2}, \mathrm{UiO}-67-\mathrm{WO}\left(\mathrm{O}_{2}\right)_{2}$ and $\mathrm{UiO}-67-\mathrm{KVO}\left(\mathrm{O}_{2}\right)_{2}$.

Table 1. The specific surface area and mass fraction of active metal of modified metal-organic frameworks (MOFs).

\begin{tabular}{ccccc}
\hline \multirow{2}{*}{ MOFs } & Metal Loading & Metal Loading & Metal/MOF & $S_{\text {BET }}$ \\
\cline { 2 - 5 } & $\mathbf{w t} \%$ & $\mathbf{m m o l} / \mathbf{g}$ & Molar Ratio & $\mathbf{m}^{\mathbf{2}} / \mathbf{g}$ \\
\hline $\mathrm{UiO}-67$ & - & - & - & 1562 \\
$\mathrm{UiO}-67-\mathrm{MoO}\left(\mathrm{O}_{2}\right)_{2}$ & $14.1(\mathrm{Mo})$ & $1.47(\mathrm{Mo})$ & $4.2(\mathrm{Mo})$ & 583 \\
$\mathrm{UiO}-67-\mathrm{WO}\left(\mathrm{O}_{2}\right)_{2}$ & $6.3(\mathrm{~W})$ & $0.34(\mathrm{~W})$ & $0.8(\mathrm{~W})$ & 656 \\
$\mathrm{UiO}-67-\mathrm{KVO}\left(\mathrm{O}_{2}\right)_{2}$ & $2.7(\mathrm{~V})$ & $0.53(\mathrm{~V})$ & $1.2(\mathrm{~V})$ & 305 \\
\hline
\end{tabular}




\subsubsection{SEM}

As shown in Figure 3, the SEM micrograph of $\mathrm{UiO}-67-\mathrm{KVO}\left(\mathrm{O}_{2}\right)_{2}$ shows that the particle size was uniform at around $60 \mathrm{~nm}$, but no obvious regular octahedron shape of UiO-67 material was observed. The reason for this might be due to the stirring during the synthesis, which has a negative effect on the growth of regular crystals.

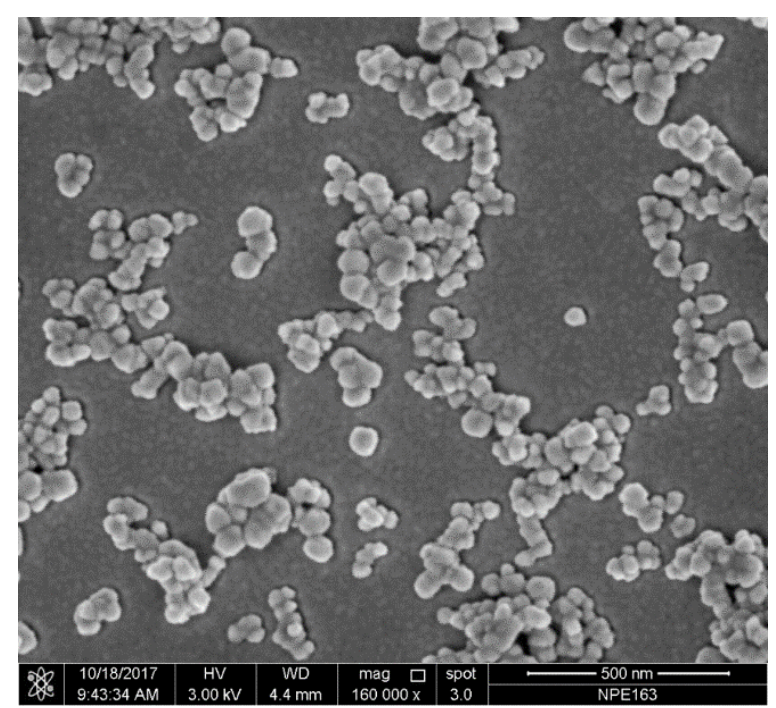

Figure 3. SEM of $\mathrm{UiO}-67-\mathrm{KVO}\left(\mathrm{O}_{2}\right)_{2}$.

\subsubsection{X-ray Photoelectron Spectroscopy}

X-ray photoelectron spectroscopy (XPS) is an advanced analytical technique in microscopic analysis of electronic materials and components and is used for investigating the electronic characteristics of the species created on the surface, including the environment of electron, state of oxidation, and the binding energy of the core electron of the metal [45]. An XPS elemental survey scan of the surface of the $\mathrm{UiO}-67-\mathrm{KVO}\left(\mathrm{O}_{2}\right)_{2}$ is shown in Figure 4. The peaks related to $\mathrm{O} 1 \mathrm{~s}, \mathrm{C} 1 \mathrm{~s}$, and $\mathrm{N} 1 \mathrm{~s}$ were observed in this spectrum (Figure $4 \mathrm{a}$ ). In Figure $4 \mathrm{~b}, \mathrm{UiO}-67-\mathrm{KVO}\left(\mathrm{O}_{2}\right)_{2}$ shows peaks at $523.7 \mathrm{eV}$ and $516.3 \mathrm{eV}$, which correspond to V $2 \mathrm{p}_{1 / 2}$ and V $2 \mathrm{p}_{3 / 2}$ of $\mathrm{V}^{5+}[46]$.

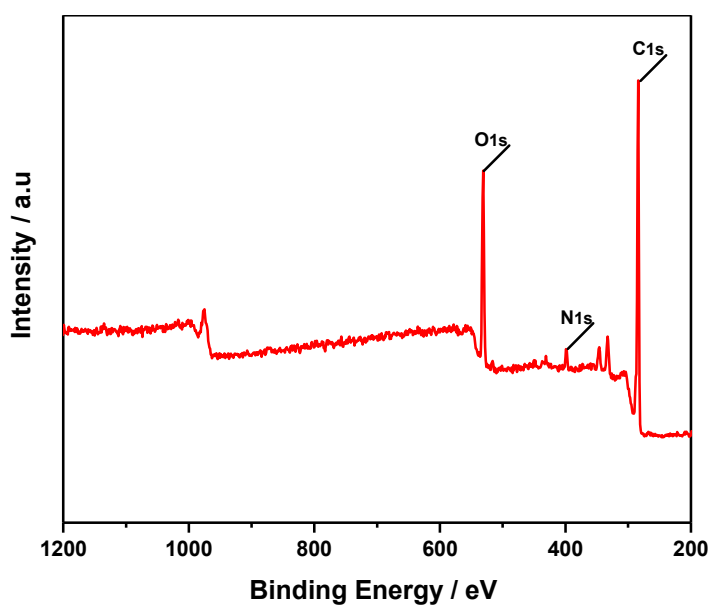

(a)

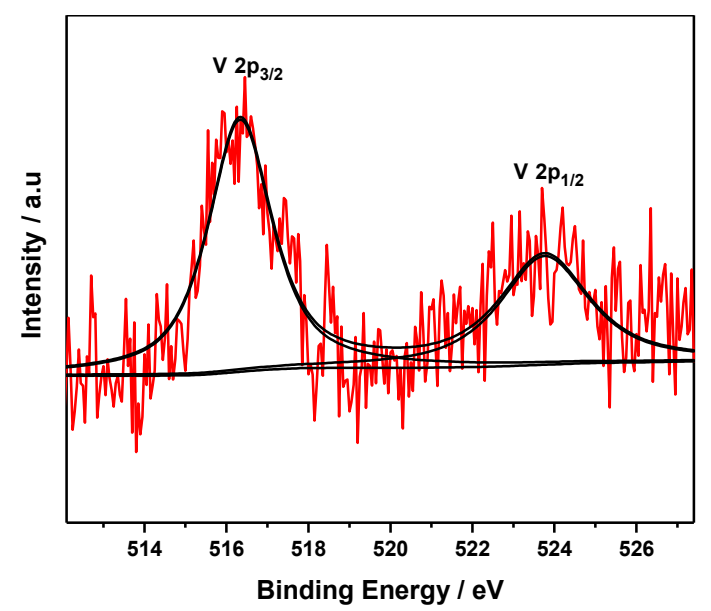

(b)

Figure 4. XPS spectra of $\mathrm{UiO}-67-\mathrm{KVO}\left(\mathrm{O}_{2}\right)_{2}(\mathbf{a})$ and $\mathrm{V} 2 \mathrm{p}$ of $\mathrm{UiO}-67-\mathrm{KVO}\left(\mathrm{O}_{2}\right)_{2}(\mathbf{b})$. 


\subsection{Catalytic Performance}

The catalytic activity of metal oxodiperoxo complex modified UiO-67 materials was investigated in the liquid phase oxidation of cyclohexane at $343 \mathrm{~K}$ with TBHP as the oxidant. The XRD patterns of the three metal oxodiperoxo complex modified UiO-67s before and after catalysis are shown in Figure 5 . It is shown that the diffraction peaks were basically unchanged, indicating that the structural robustness of the material was fully retained during the reaction. The catalytic conversion and selectivity are shown in detail in Table 2. In the MOF modification process, the binding ability of different active metal components to the ligand is different, and it is difficult to ensure that the active metal M/MOF molar ratio is the same. Therefore, in the cyclohexane oxidation reaction, the amount of different catalysts was controlled based on the molar amount of the active metal. The molar ratio of cyclohexane to active metal ( $\mathrm{CH}: \mathrm{M})$ was fixed to 266. Blank experiments were carried out to ensure the role of the active sites in the selective oxidation of cyclohexane. As summarized in Table 2, without adding any catalyst to the reaction mixture, negligible conversion of cyclohexane was observed; when UiO-67 was added to the reaction mixture, a low conversion of cyclohexane was observed, with CHHP as the major product. The formation of CHHP is mainly catalyzed by certain amounts of unsaturated zirconium sites on UiO-67. Compared to UiO-67-KVO $\left(\mathrm{O}_{2}\right)_{2}$, UiO-67-MoO $\left(\mathrm{O}_{2}\right)_{2}$ and $\mathrm{UiO}-67-\mathrm{WO}\left(\mathrm{O}_{2}\right)_{2}$ catalyzed the cyclohexane oxidation with a very low cyclohexane conversion, and, similarly, CHHP was the main product, indicating only a minor contribution from the catalyst. On the other hand, it is clearly noticed that UiO-67- $\mathrm{KVO}\left(\mathrm{O}_{2}\right)_{2}$ was more active in the oxidation of cyclohexane, with a relatively higher cyclohexane conversion of $9.4 \%$ in $12 \mathrm{~h}$. This observation was in agreement with the earlier report, which confirmed that the vanadium $(\mathrm{V})$ oxodiperoxo complexes had the ability to transfer oxygen to aromatic hydrocarbons, acting as powerful epoxidizing and hydroxylating reagents.

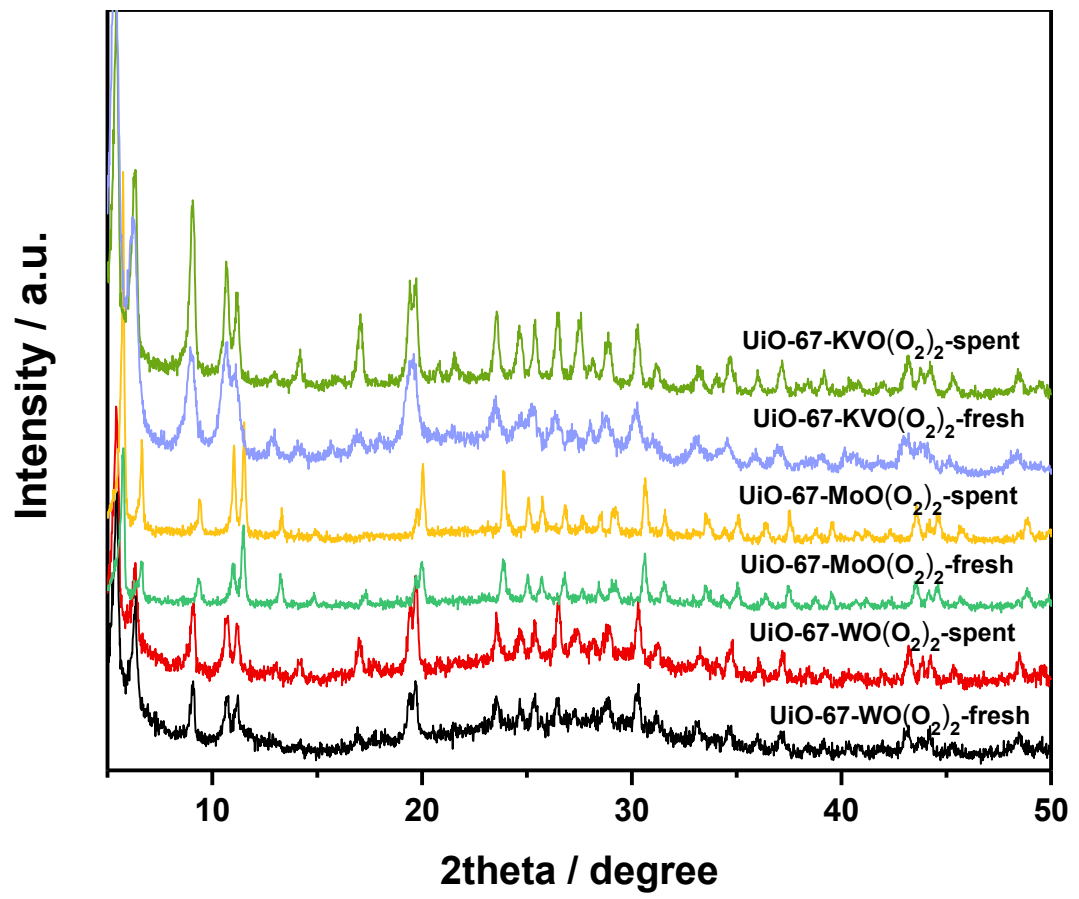

Figure 5. XRD patterns of $\mathrm{UiO}-67-\mathrm{MoO}\left(\mathrm{O}_{2}\right)_{2}$, $\mathrm{UiO}-67-\mathrm{WO}\left(\mathrm{O}_{2}\right)_{2}$, and $\mathrm{UiO}-67-\mathrm{KVO}\left(\mathrm{O}_{2}\right)_{2}$ before and after reactions.

The trend in cyclohexane conversion and selectivity over time is shown in Figure 6a. The cyclohexane conversion increased to $6.3 \%$ in $6 \mathrm{~h}$, slowly reached $9.4 \%$ conversion in $12 \mathrm{~h}$, and remained almost constant afterward. However, the selectivities towards $\mathrm{Cyone}, \mathrm{CyOH}$, and $\mathrm{CHHP}$ were quite different over time. While increasing the reaction time, the selectivity toward Cyone had a constant increase from $46.2 \%$ at $6 \mathrm{~h}$ up to a maximum value of $86.9 \%$ at $24 \mathrm{~h}$. The intermediate product, CHHP, 
decreased slowly, while the selectivity toward $\mathrm{CyOH}$ decreased over time as well, and no $\mathrm{CyOH}$ was observed after $24 \mathrm{~h}$. While in a prolonged reaction timeframe, the selectivity to the by-product acids increased slowly. These results showed that a longer reaction time promoted the decomposition of the intermediate $\mathrm{CHHP}$ to afford the main product, $\mathrm{CyOH}$ and $\mathrm{CyOne}$, whereas further prolongation of the reaction time led to an increased Cyone formation and decreased $\mathrm{CyOH}$ formation. The total selectivity toward the main product, KA oil, increased monotonically with time. Thus, the optimum reaction time was $24 \mathrm{~h}$. To exclude the contribution of leached V species in the solution, a hot-filtration experiment was performed. After $6 \mathrm{~h}$ of reaction, the solid catalyst was removed from the reaction mixture by filtration, and the filtrate was recovered to continue the reaction under the same condition for an additional $6 \mathrm{~h}$. Figure $6 \mathrm{~b}$ indicates that the conversion of cyclohexane remained stable after the catalyst was filtered off, suggesting that the cyclohexane oxidation was terminated after removal of the solid catalyst (with the catalyst, the cyclohexane conversion reached $9.4 \%$ after $12 \mathrm{~h}$ ).

Table 2. The result of cyclohexane oxidation catalyzed by metal peroxide modified $\mathrm{UiO}-67^{\mathrm{a}}$.

\begin{tabular}{|c|c|c|c|c|c|c|c|}
\hline \multirow{2}{*}{ Catalyst } & \multirow{2}{*}{ Time/h } & \multirow{2}{*}{$\begin{array}{c}\text { Conversion } \\
\mathrm{b} / \%\end{array}$} & \multicolumn{5}{|c|}{ Selectivity ${ }^{c} / \%$} \\
\hline & & & СуОН & Cyone & KA oil & СНHР & Others $^{d}$ \\
\hline No catalyst & 12 & $<1$ & - & - & - & - & - \\
\hline $\mathrm{UiO}-67$ & 12 & 1.3 & 13.4 & 35.8 & 49.2 & 50.8 & - \\
\hline $\mathrm{UiO}-67-\mathrm{MoO}\left(\mathrm{O}_{2}\right)_{2}$ & 12 & $<1$ & - & 33.2 & 33.2 & 66.8 & - \\
\hline $\mathrm{UiO}-67-\mathrm{WO}\left(\mathrm{O}_{2}\right)_{2}$ & 12 & 1.6 & 16.2 & 23.2 & 39.4 & 60.6 & - \\
\hline $\mathrm{UiO}-67-\mathrm{KVO}\left(\mathrm{O}_{2}\right)_{2}$ & 12 & 9.4 & 18.5 & 58.5 & 77.0 & 12.2 & 10.8 \\
\hline $\mathrm{UiO}-67-\mathrm{KVO}\left(\mathrm{O}_{2}\right)_{2}$ & 24 & 9.2 & - & 86.9 & 86.9 & - & 13.1 \\
\hline $\mathrm{UiO}-67-\mathrm{KVO}\left(\mathrm{O}_{2}\right)_{2}$ & 6 & 6.3 & 25.1 & 46.2 & 71.3 & 22.0 & 6.7 \\
\hline $\begin{array}{l}\mathrm{UiO}-67-\mathrm{KVO}\left(\mathrm{O}_{2}\right)_{2} \\
\text { after hot filtration }\end{array}$ & 12 & 6.5 & 22.4 & 49.3 & 71.7 & 21.8 & 6.5 \\
\hline $\mathrm{H}_{2}$ bpydc-KVO $\left(\mathrm{O}_{2}\right)_{2}$ & 12 & 7.4 & 18.8 & 68.3 & 87.1 & 9.2 & 3.8 \\
\hline
\end{tabular}

${ }^{\mathrm{a}}$ Reaction conditions: CH:M (molar ratio) $=266$, CH:TBHP (molar ratio) $=1: 1, \mathrm{~T}$ (temperature) $=343 \mathrm{~K}$.

$\mathrm{b}$ Conversion/\% based on cyclohexane $=$ total moles of products after reaction $/$ moles of cyclohexane before reaction $\times 100{ }^{c}$ Selectivity $/ \%$ of product $=$ moles of product after reaction/total moles of products. ${ }^{d}$ Others are mainly organic acid (quantified based on the titration result with $\mathrm{NaOH}$ ); no ester product was found based on the titration result. ${ }^{\text {e }}$ Hot filtration: The reaction stopped after $6 \mathrm{~h}$, the catalyst was filtered off, and the filtrate was left to continue to react under the same condition for another $6 \mathrm{~h}$.

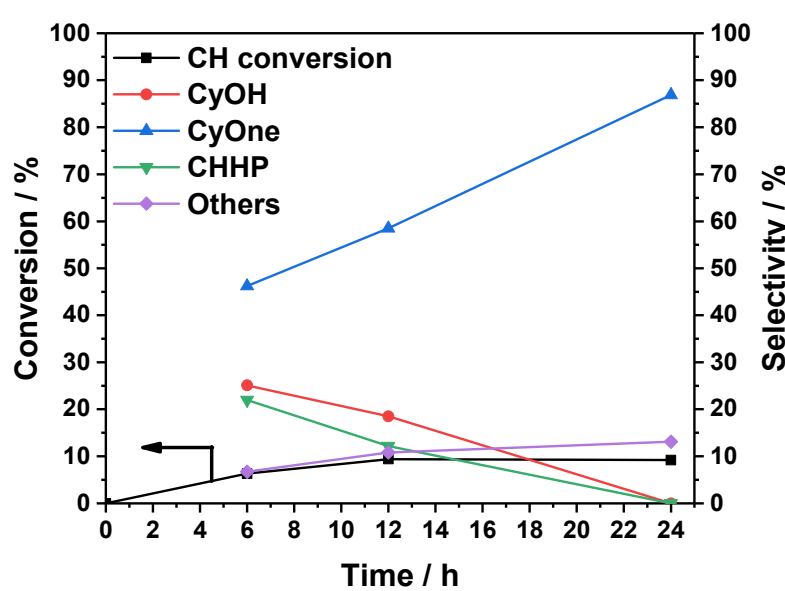

(a)

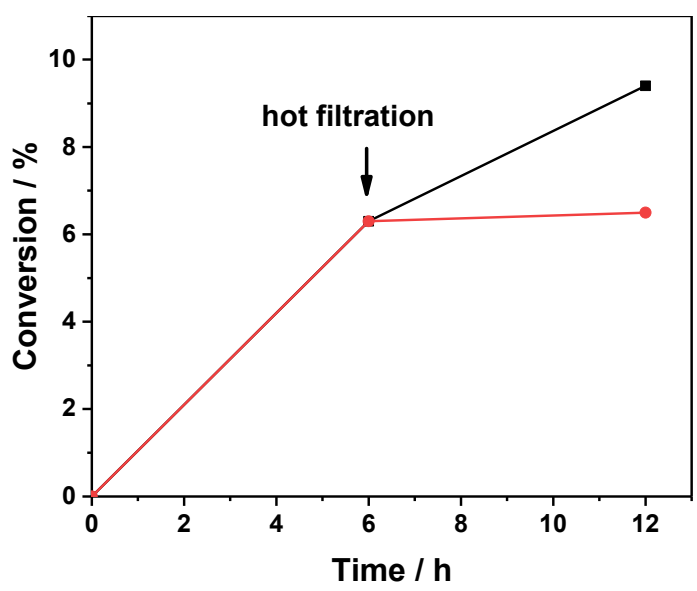

(b)

Figure 6. (a) Effect of reaction time on cyclohexane conversion and product selectivity catalyzed by UiO-67-KVO $\left(\mathrm{O}_{2}\right)_{2}$. Reaction conditions: $\mathrm{CH}: \mathrm{M}$ (molar ratio) = 266, $\mathrm{T}=343 \mathrm{~K}$; (b) Cyclohexane conversion (\%) in the hot-filtration reaction over $\mathrm{UiO}-67-\mathrm{KVO}\left(\mathrm{O}_{2}\right)_{2}$.

The XPS spectra of $\mathrm{UiO}-67-\mathrm{KVO}\left(\mathrm{O}_{2}\right)_{2}$ before and after reaction are illustrated in Figure 7. The V 2 $\mathrm{p}_{1 / 2}$ and V 2 $\mathrm{p}_{3 / 2}$ peak binding energy shifted from $523.7 \mathrm{eV}$ and $516.3 \mathrm{eV}$ (Figure 7a) to $524.4 \mathrm{eV}$ 
and $517.0 \mathrm{eV}$ (Figure $7 \mathrm{~b}$ ), respectively, with an $0.7 \mathrm{eV}$ offset of both peaks. This is the characteristic of $\mathrm{V}^{5+}[47,48]$, confirming no obvious change in the valence state of $\mathrm{V}$ over the catalysis before and after reactions.

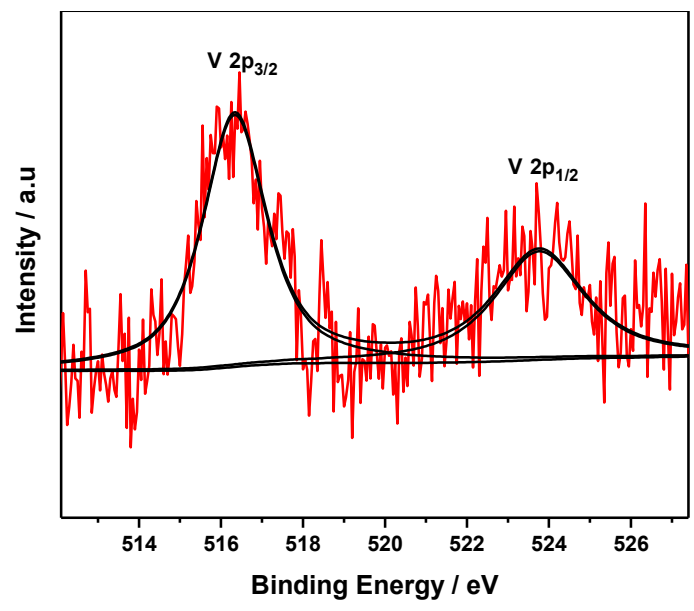

(a)

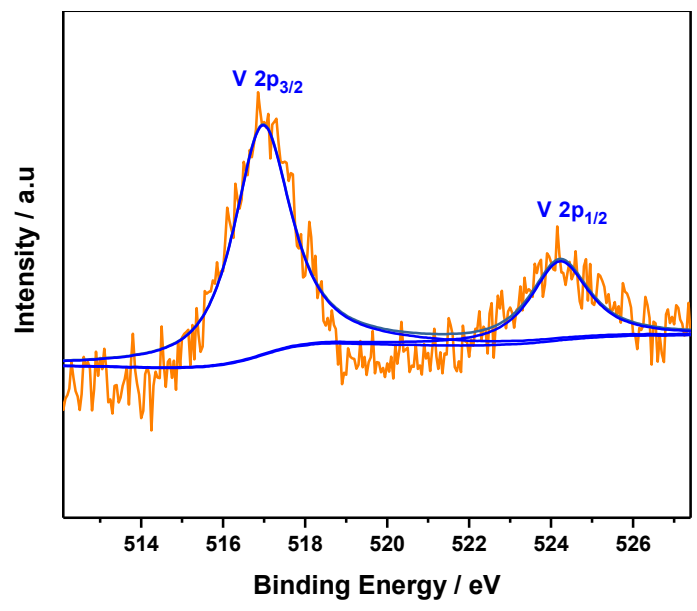

(b)

Figure 7. XPS spectra of $\mathrm{V} 2 \mathrm{p}$ of $\mathrm{UiO}-67-\mathrm{KVO}\left(\mathrm{O}_{2}\right)_{2}$ before $(\mathbf{a})$ and after $(\mathbf{b})$ reactions.

Among several metal oxodiperoxo complex modified $\mathrm{UiO}-67, \mathrm{UiO}-67-\mathrm{KVO}\left(\mathrm{O}_{2}\right)_{2}$ showed the best catalytic activity. In Table 3, a comparison between the reported vanadium-based silica, phosphorus, or mesoporous catalysts with $\mathrm{UiO}-67-\mathrm{KVO}\left(\mathrm{O}_{2}\right)_{2}$ of the current study is summarized. All the catalytic reactions used TBHP as the oxidant, and $\mathrm{UiO}-67-\mathrm{KVO}\left(\mathrm{O}_{2}\right)_{2}$ showed the second best selectivity toward KA oil (77\%) with Cyone as the major product. V-Co-TUD-1, a cobalt promoted vanadium based mesoporous siliceous material, showed the best selectivity toward KA oil (87.9\%) in a solvent free condition, and $\mathrm{CyOH}$ was the major product. The vanadium phosphorus oxide (VPO) and VPO-Co(0.10) (cobalt promoted VPO) catalysts showed similar selectivity toward KA oil, around 53\% 55\%, and the by-product for the VPO catalysts was mainly cyclohexene. However, cobalt doping significantly increased the overall activity for the oxidation of cyclohexane from $10 \%$ to $65 \%$. Therefore, our future planning work includes the further tethering of $\mathrm{Co}^{2+}$ ions into $\mathrm{UiO}-67-\mathrm{KVO}\left(\mathrm{O}_{2}\right)_{2}$ to investigate the effect toward the liquid phase oxidation of cyclohexane.

Table 3. Comparison of cyclohexane oxidation in $\mathrm{MeCN}$ solution by various vanadium based catalysts.

\begin{tabular}{|c|c|c|c|c|c|c|c|c|c|}
\hline \multirow{2}{*}{ Catalyst } & \multirow{2}{*}{ Time/h } & \multirow{2}{*}{ Temp. $/{ }^{\circ} \mathrm{C}$} & \multirow{2}{*}{$\begin{array}{c}\text { Conv. } \\
\text { a } / \%\end{array}$} & \multicolumn{5}{|c|}{ Selectivity } & \multirow{2}{*}{ Refs } \\
\hline & & & & $\mathrm{CyOH}$ & Cyone & KA oil & CHHP & Others & \\
\hline $\mathrm{UiO}-67-\mathrm{KVO}\left(\mathrm{O}_{2}\right)_{2}$ & 12 & 70 & 9.4 & 18.5 & 58.5 & 77.0 & 13.1 & 10.8 & This work \\
\hline V-Co-TUD-1 ${ }^{\mathrm{c}}$ & 8 & 70 & 15.9 & 62 & 25.9 & 87.9 & 2.4 & 9.7 & {$[21]$} \\
\hline VPO & 8 & 90 & 10 & 33 & 22 & 55 & - & $45^{\mathrm{b}}$ & [49] \\
\hline VPO-Co(0.10) & 8 & 90 & 65 & 20 & 33 & 53 & - & $47^{\mathrm{b}}$ & [49] \\
\hline
\end{tabular}

${ }^{\mathrm{a}}$ TBHP as the oxidant, ${ }^{\mathrm{b}}$ Cyclohexene, ${ }^{\mathrm{c}}$ Solvent free.

\section{Conclusions}

In the present study, characterization results confirmed that $\mathrm{UiO}-67-\mathrm{MoO}\left(\mathrm{O}_{2}\right)_{2}, \mathrm{UiO}-67-\mathrm{WO}\left(\mathrm{O}_{2}\right)_{2}$, and $\mathrm{UiO}-67-\mathrm{KVO}\left(\mathrm{O}_{2}\right)_{2}$ was obtained, and the transition metal oxodiperoxo complexes $\left(\mathrm{MoO}\left(\mathrm{O}_{2}\right)_{2}\right.$, $\mathrm{WO}\left(\mathrm{O}_{2}\right)_{2}$, and $\left.\mathrm{KVO}\left(\mathrm{O}_{2}\right)_{2}\right)$ were anchored on the framework by coordination. UiO-67- $\mathrm{KVO}\left(\mathrm{O}_{2}\right)_{2}$ showed the best catalytic performance in the liquid phase oxidation of cyclohexane with TBHP as the oxidant. The effect of reaction time in the reaction is critical. Cyclohexane conversion reached the highest value of $9.4 \%$ at $12 \mathrm{~h}$, and further prolongation of reaction time led to an increased Cyone 
formation and a decreased $\mathrm{CyOH}$ formation. The selectivity towards the main product, KA oil, increased constantly over time. Hot-filtration experiment excluded the leaching of $\mathrm{V}$ species and its contribution to the catalytic reaction.

Supplementary Materials: The following are available online at http://www.mdpi.com/1996-1944/13/4/829/s1, Figure S1: FT-IR spectra of $\mathrm{H}_{2}$ bpydc, $\mathrm{H}_{2}$ bpydc- $\mathrm{KVO}\left(\mathrm{O}_{2}\right)_{2}$ and $\mathrm{H}_{2}$ bpydc- $\mathrm{WO}\left(\mathrm{O}_{2}\right)_{2}$, Figure S2: XRD patterns of UiO-67- $\mathrm{MoO}\left(\mathrm{O}_{2}\right)_{2}$ and $\mathrm{UiO}-67-\mathrm{KVO}\left(\mathrm{O}_{2}\right)_{2}$ in different drying temperature, Table S1: The ICP and elemental analysis results of $\mathrm{H}_{2}$ bpydc- $\mathrm{KVO}\left(\mathrm{O}_{2}\right)_{2}$ and $\mathrm{H}_{2}$ bpydc- $\mathrm{WO}\left(\mathrm{O}_{2}\right)_{2}$.

Author Contributions: Y.H. performed the catalyst characterization and the catalytic activity tests, and wrote the original draft; J.P. synthesized the catalyst and built the analysis formula to quantify the products; Z.Y. and Z.S. performed the catalyst characterization and reviewed the manuscript; A.W. and Y.W. reviewed and edited the manuscript; Y.-Y.L. supervised the project and edited the manuscript; F.X. and L.-X.S. provided XPS measurements and analysis. All authors have read and agreed to the published version of the manuscript.

Funding: International S\&T Cooperation Program of China (2016YFE0109800), National Natural Science Foundation of China (21972014, 21603024, U1508205, 21403025, 21473017), and the Fundamental Research Funds for the Central Universities (DUT19GJ205), Guangxi Key Laboratory of Information Materials research fund (191006-K)

Conflicts of Interest: The authors declare no conflict of interest.

\section{References}

1. Long, J.; Wang, L.; Gao, X.; Bai, C.; Jiang, H.; Li, Y. Activation of molecular oxygen by a metal-organic framework with open 2,2'-bipyridine for selective oxidation of saturated hydrocarbons. Chem. Commun. 2012, 48, 12109-12111. [CrossRef] [PubMed]

2. Perkas, N.; Koltypin, Y.; Palchik, O.; Gedanken, A.; Chandrasekaran, S. Oxidation of cyclohexane with nanostructured amorphous catalysts under mild conditions. Appl. Catal. A Gen. 2001, 209, 125-130. [CrossRef]

3. Kumar, R.; Sithambaram, S.; Suib, S.L. Cyclohexane oxidation catalyzed by manganese oxide octahedral molecular sieves-Effect of acidity of the catalyst. J. Catal. 2009, 262, 304-313. [CrossRef]

4. Schuchardt, U.; Cardoso, D.; Sercheli, R.; Pereira, R.; Da Cruz, R.S.; Guerreiro, M.C.; Mandelli, D.; Spinacé, E.V.; Pires, E.L. Cyclohexane oxidation continues to be a challenge. Appl. Catal. A Gen. 2001, 211,1-17. [CrossRef]

5. Jing, B.; LI, J.; Qin, Z. Selective oxidation of cyclohexane over Co-APO-5: Effects of solvent and modification method on the catalytic performance. J. Fuel Chem. Technol. 2016, 44, 1249-1258. [CrossRef]

6. Wang, J.; Ding, F.; Ma, J.; Liu, Q.; Cheng, J.; Dong, Y. Co(II)-MOF: A Highly Efficient Organic Oxidation Catalyst with Open Metal Sites. Inorg. Chem. 2015, 54, 10865-10872. [CrossRef]

7. Wu, P.; Cao, Y.; Wang, Y.; Xing, W.; Zhong, Z.; Bai, P.; Yan, Z. Ultrastable bimetallic catalyst with tuned surface electronic properties for highly selective oxidation of cyclohexane. Appl. Surf. Sci. 2018, 457, 580-590. [CrossRef]

8. Sun, L.; Liu, J.; Luo, W.; Yang, Y.; Wang, F.; Weerakkody, C.; Suib, S.L. Preparation of amorphous copper-chromium oxides catalysts for selective oxidation of cyclohexane. Mol. Catal. 2018, 460, 16-26. [CrossRef]

9. Maksimchuk, N.V.; Kovalenko, K.A.; Fedin, V.P.; Kholdeeva, O.A. Cyclohexane selective oxidation over metal-organic frameworks of MIL-101 family: Superior catalytic activity and selectivity. Chem. Commun. 2012, 48, 6812-6814. [CrossRef]

10. Acharyya, S.S.; Ghosh, S.; Adak, S.; Tripathi, D.; Bal, R. Fabrication of $\mathrm{CuCr}_{2} \mathrm{O}_{4}$ spinel nanoparticles: A potential catalyst for the selective oxidation of cycloalkanes via activation of $\mathrm{Csp}_{3}-\mathrm{H}$ bond. Catal. Commun. 2015, 59, 145-150. [CrossRef]

11. Goldstein, A.S.; Beer, R.H.; Drago, R.S. Catalytic Oxidation of Hydrocarbons with $\mathrm{O}_{2}$ or $\mathrm{H}_{2} \mathrm{O}_{2}$ Using a Sterically Hindered Ruthenium Complex. J. Am. Chem. Soc. 1994, 116, 2424-2429. [CrossRef]

12. Martins, N.M.R.; Pombeiro, A.J.L.; Martins, L.M.D.R.S. Green oxidation of cyclohexane catalyzed by recyclable magnetic transition-metal silica coated nanoparticles. Catal. Commun. 2019, 125, 15-20. [CrossRef]

13. Hereijgers, B.P.C.; Weckhuysen, B.M. Aerobic oxidation of cyclohexane by gold-based catalysts: New mechanistic insight by thorough product analysis. J. Catal. 2010, 270, 16-25. [CrossRef]

14. Graça, I.; Al-Shihri, S.; Chadwick, D. Selective oxidation of cyclohexane: Ce promotion of nanostructured manganese tungstate. Appl. Catal. A Gen. 2018, 568, 95-104. [CrossRef] 
15. Stultz, L.K.; Huynh, M.H.V.; Binstead, R.A.; Curry, M.; Meyer, T.J. Allylic Oxidation of Cyclohexene and Indene by cis-[Ru $\left.{ }^{\mathrm{IV}}(\mathrm{bpy})_{2}(\mathrm{py})(\mathrm{O})\right]^{2+}$. J. Am. Chem. Soc. 2000, 122, 5984-5996. [CrossRef]

16. Sutradhar, M.; Barman, T.; Pombeiro, A.; Martins, L. Catalytic Activity of Polynuclear vs. Dinuclear Aroylhydrazone $\mathrm{Cu}(\mathrm{II})$ Complexes in Microwave-Assisted Oxidation of Neat Aliphatic and Aromatic Hydrocarbons. Molecules 2019, 24, 47. [CrossRef]

17. Wu, K.; Li, B.; Han, C.; Liu, J. Synthesis, characterization of MCM-41 with high vanadium content in the framework and its catalytic performance on selective oxidation of cyclohexane. Appl. Catal. A Gen. 2014, 479, 70-75. [CrossRef]

18. Shylesh, S.; Singh, A. Heterogenized vanadyl cations over modified silica surfaces: A comprehensive understanding toward the structural property and catalytic activity difference over mesoporous and amorphous silica supports. J. Catal. 2006, 244, 52-64. [CrossRef]

19. Santra, C.; Shah, S.; Mondal, A.; Pandey, J.K.; Panda, A.B.; Maity, S.; Chowdhury, B. Synthesis, characterization of VPO catalyst dispersed on mesoporous silica surface and catalytic activity for cyclohexane oxidation reaction. Microporous Mesoporous Mater. 2016, 223, 121-128. [CrossRef]

20. Anand, R.; Hamdy, M.S.; Parton, R.; Maschmeyer, T.; Jansen, J.C.; Gläser, R.; Kapteijn, F.; Hanefeld, U. Metal-TUD-1 Catalyzed Aerobic Oxidation of Cyclohexane: A Comparative Study. Aust. J. Chem. 2009, 62, 360-365. [CrossRef]

21. Alshehri, A.A.; Alhanash, A.M.; Eissa, M.; Hamdy, M.S. New catalysts with dual-functionality for cyclohexane selective oxidation. Appl. Catal. A Gen. 2018, 554, 71-79. [CrossRef]

22. Anand, R.; Hamdy, M.S.; Hanefeld, U.; Maschmeyer, T. Liquid-Phase Oxidation of Cyclohexane over Co-TUD-1. Catal. Lett. 2004, 95, 113-117. [CrossRef]

23. Hamdy, M.S.; Ramanathan, A.; Maschmeyer, T.; Hanefeld, U.; Jansen, J.C. Co-TUD-1: A Ketone-Selective Catalyst for Cyclohexane Oxidation. Chem. Eur. J. 2006, 12, 1782-1789. [CrossRef] [PubMed]

24. Aboelfetoh, E.F.; Fechtelkord, M.; Pietschnig, R. Structure and catalytic properties of MgO-supported vanadium oxide in the selective oxidation of cyclohexane. J. Mol. Catal. A Chem. 2010, 318, 51-59. [CrossRef]

25. Aboelfetoh, E.F.; Pietschnig, R. Preparation and Catalytic Performance of $\mathrm{Al}_{2} \mathrm{O}_{3}, \mathrm{TiO}_{2}$ and $\mathrm{SiO}_{2}$ Supported Vanadium Based-Catalysts for C-H Activation. Catal. Lett. 2009, 127, 83-94. [CrossRef]

26. Pal, N.; Pramanik, M.; Bhaumik, A.; Ali, M. Highly selective and direct oxidation of cyclohexane to cyclohexanone over vanadium exchanged $\mathrm{NaY}$ at room temperature under solvent-free conditions. J. Mol. Catal. A Chem. 2014, 392, 299-307. [CrossRef]

27. Noh, H.; Cui, Y.; Peters, A.W.; Pahls, D.R.; Ortuño, M.A.; Vermeulen, N.A.; Cramer, C.J.; Gagliardi, L.; Hupp, J.T.; Farha, O.K. An Exceptionally Stable Metal-Organic Framework Supported Molybdenum(VI) Oxide Catalyst for Cyclohexene Epoxidation. J. Am. Chem. Soc. 2016, 138, 14720-14726. [CrossRef]

28. Li, Y.; Wei, Z.; Liu, L.; Gao, M.; Han, Z. Ag nanoparticles supported on UiO-66 for selective oxidation of styrene. Inorg. Chem. Commun. 2018, 88, 47-50. [CrossRef]

29. Stock, N.; Biswas, S. Synthesis of Metal-Organic Frameworks (MOFs): Routes to Various MOF Topologies, Morphologies, and Composites. Chem. Rev. 2012, 112, 933-969. [CrossRef]

30. Liu, Y.; Leus, K.; Grzywa, M.; Weinberger, D.; Strubbe, K.; Vrielinck, H.; Van Deun, R.; Volkmer, D.; Van Speybroeck, V.; Van Der Voort, P. Synthesis, Structural Characterization, and Catalytic Performance of a Vanadium-Based Metal-Organic Framework (COMOC-3). Eur. J. Inorg. Chem. 2012, 2819-2827. [CrossRef]

31. Fei, H.; Cohen, S.M. A robust, catalytic metal-organic framework with open 2,2'-bipyridine sites. Chem. Commun. 2014, 50, 4810-4812. [CrossRef]

32. Liu, Y.; Leus, K.; Sun, Z.; Li, X.; Depauw, H.; Wang, A.; Zhang, J.; Van Der Voort, P. Catalytic oxidative desulfurization of model and real diesel over a molybdenum anchored metal-organic framework. Microporous Mesoporous Mater. 2019, 277, 245-252. [CrossRef]

33. Leus, K.; Liu, Y.; Meledina, M.; Turner, S.; Van Tendeloo, G.; Van Der Voort, P. A Mo ${ }^{\text {VI }}$ grafted Metal Organic Framework: Synthesis, characterization and catalytic investigations. J. Catal. 2014, 316, 201-209. [CrossRef]

34. Manna, K.; Zhang, T.; Greene, F.X.; Lin, W. Bipyridine- and Phenanthroline-Based Metal-Organic Frameworks for Highly Efficient and Tandem Catalytic Organic Transformations via Directed C-H Activation. J. Am. Chem. Soc. 2015, 137, 2665-2673. [CrossRef]

35. Wang, S.; Sun, Z.; Zou, X.; Zhang, Z.; Fu, G.; Li, L.; Zhang, X.; Luo, F. Enhancing catalytic aerobic oxidation performance of cyclohexane via size regulation of mixed-valence $\{$ V16 $\}$ cluster-based metal-organic frameworks. New J. Chem. 2019, 43, 14527-14535. [CrossRef] 
36. Rimoldi, M.; Howarth, A.J.; DeStefano, M.R.; Lin, L.; Goswami, S.; Li, P.; Hupp, J.T.; Farha, O.K. Catalytic Zirconium/Hafnium-Based Metal-Organic Frameworks. ACS Catal. 2017, 7, 997-1014. [CrossRef]

37. Cavka, J.H.; Jakobsen, S.; Olsbye, U.; Guillou, N.; Lamberti, C.; Bordiga, S.; Lillerud, K.P. A New Zirconium Inorganic Building Brick Forming Metal Organic Frameworks with Exceptional Stability. J. Am. Chem. Soc. 2008, 130, 13850-13851. [CrossRef] [PubMed]

38. Peterson, G.W.; Moon, S.; Wagner, G.W.; Hall, M.G.; De Coste, J.B.; Hupp, J.T.; Farha, O.K. Tailoring the Pore Size and Functionality of UiO-Type Metal-Organic Frameworks for Optimal Nerve Agent Destruction. Inorg. Chem. 2015, 54, 9684-9686. [CrossRef] [PubMed]

39. Szeto, K.C.; Kongshaug, K.O.; Jakobsen, S.; Tilset, M.; Lillerud, K.P. Design, synthesis and characterization of a Pt-Gd metal-organic framework containing potentially catalytically active sites. Dalton Trans. 2008, 2054-2060. [CrossRef]

40. Tang, J.; Dong, W.; Wang, G.; Yao, Y.; Cai, L.; Liu, Y.; Zhao, X.; Xu, J.; Tan, L. Efficient molybdenum(vi) modified Zr-MOF catalysts for epoxidation of olefins. RSC Adv. 2014, 4, 42977-42982. [CrossRef]

41. Das, S.P.; Boruah, J.J.; Sharma, N.; Islam, N.S. New polymer-immobilized peroxotungsten compound as an efficient catalyst for selective and mild oxidation of sulfides by hydrogen peroxide. J. Mol. Catal. A Chem. 2012, 356, 36-45. [CrossRef]

42. Yu, X.; Yi, P.; Ji, D.; Zeng, B.; Li, X.; Xu, X. Study of the coordination and solution structures for the interaction systems between diperoxidovanadate complexes and 4-(pyridin-2-yl)pyrimidine-like ligands. Dalton Trans. 2012, 41, 3684-3694. [CrossRef] [PubMed]

43. Wang, Z.; Cohen, S.M. Postsynthetic modification of metal-organic frameworks. Chem. Soc. Rev. 2009, 38, 1315-1329. [CrossRef]

44. Sarmah, S.; Kalita, D.; Hazarika, P.; Borah, R.; Islam, N.S. Synthesis of new dinuclear and mononuclear peroxovanadium $(\mathrm{V})$ complexes containing biogenic co-ligands: A comparative study of some of their properties. Polyhedron 2004, 23, 1097-1107. [CrossRef]

45. Veisi, H.; Sajjadifar, S.; Biabri, P.M.; Hemmati, S. Oxo-vanadium complex immobilized on chitosan coated-magnetic nanoparticles $\left(\mathrm{Fe}_{3} \mathrm{O}_{4}\right)$ : A heterogeneous and recyclable nanocatalyst for the chemoselective oxidation of sulfides to sulfoxides with $\mathrm{H}_{2} \mathrm{O}_{2}$. Polyhedron 2018, 153, 240-247. [CrossRef]

46. Silversmit, G.; Depla, D.; Poelman, H.; Marin, G.B.; De Gryse, R. Determination of the V2p XPS binding energies for different vanadium oxidation states $\left(\mathrm{V}^{5+}\right.$ to $\left.\mathrm{V}^{0+}\right)$. J. Electron Spectrosc. Relat. Phenom. 2004, 135, 167-175. [CrossRef]

47. Horvath, B.; Strutz, J.; Geyer-Lippmann, J.; Horvath, E.G. Preparation, Properties, and ESCA Characterization of Vanadium Surface Compounds on Silicagel. I. Z. Anorg. Allg. Chem. 1981, 483, 181-192. [CrossRef]

48. Occhiuzzi, M.; Tuti, S.; Cordischi, D.; Dragone, R.; Indovina, V. Characterisation of $\mathrm{VO}_{\mathrm{x}} / \mathrm{ZrO}_{2}$ catalysts by electron paramagnetic resonance and X-ray photoelectron spectroscopy. J. Chem. Soc. Faraday Trans. 1996, 92, 4337-4345. [CrossRef]

49. Mahdavi, V.; Hasheminasab, H.R. Liquid-phase efficient oxidation of cyclohexane over cobalt promoted VPO catalyst using tert-butylhydroperoxide. J. Taiwan Inst. Chem. Eng. 2015, 51, 53-62. [CrossRef]

(C) 2020 by the authors. Licensee MDPI, Basel, Switzerland. This article is an open access article distributed under the terms and conditions of the Creative Commons Attribution (CC BY) license (http://creativecommons.org/licenses/by/4.0/). 